\title{
EXPERIMENTAL AND CLINICAL EXPERIENCE WITH TOXIFERINE (ALKALOID OF CALABASH CURARE)*
}

\author{
R. FREY, M.D., F.F.A.R.C.S., and R. SEeger, M.D. $\dagger$
}

The PRESENT MUSCle RELAXANT DRUGS do not yet fulfil all the desires of the anaesthetist with regard to variation of the duration of action, the possibility of being antagonized, and the avoidance of side-effects. The search for further relaxant drugs is therefore justified.

In 1958, Karrer and Schmid (Zürich) isolated the chief alkaloids from Calabash curare and determined their chemical structure. Waser investigated their pharmacological properties and subsequently, together with the anaesthetistl Harbeck (Zürich), defined the possibilities of their clillical use.

In order to form our own opinion, we used Toxiferine, the drug which is perhaps the most appropriate for clinical use, in 30 trials on conscious volunteers and 100 patients during anaesthesia, in the Department of Anaesthesia of the University Clinics, Mainz.

\section{Methods}

\section{Auto Trials}

(a) Volunteers. The three volunteers were assistants in the Department of Anaesthesia who were familiar with the action of muscle relaxants because, in the anaesthesiological practice, they had worked daily with such drugs for years. Thus we could rely on the co-operation of the volunteers and were able to sufficiently exclude any subjective influence on the results by the volunteers. In order to determine the relationship between effect and body weight, we chose volunteers (of about the same age) who differed markedly in body weight (44, 68 , and $82 \mathrm{~kg}$.).

(b) Technique of injection. The Toxiferine solution was administered intravenously. The injection time varied between 5 and $90 \mathrm{sec}$. We chose the extremely rapid injection of five seconds in order to achieve a high initial blood level enabling us, at the same time, to obtain a better understanding of possible side effects. The slower injection was studied because this lies nearer the -mrode of administration under clinical conditions or represents the pharmacologically appropriate mode of administration. In varying the speed of injection of the same dose, we were able to demonstrate variations in the inteńsity and duration of action with Toxiferine, as expected from experience with other curare preparations.

(c) Form and technique of recording. Blood pressure, pulse rate, vital capacity, respiratory rate, and grip strength were recorded at intervals of one to two

${ }^{*}$ Paper read at the World Congress of Anaesthesiologists in Toronto, Sept. 8, 1960.

†Department of Anaesthesia of the University Clinics, Mainz (Director: Professor R: Frey, M.D., F.F.A.R.C.S.).

Can. Anaes. Soc. J., vol. 8, no. 2, March, 1961. 
minutes. In addition, we registered the latent period, the duration of head drop and of paralysis of deglutition which is so important in clinical application. The grip strength was measured with the ergometer, the yital capacity with the volumeter of the anaesthetic apparatus (Draeger). We purposely renounced further spirographic measurements, firstly because additional recordings would have been impossible without prolonging the test periods and secondly because we did not want to overtire the volunteers; both would have impaired the accuracy of the results.

\section{Clinical Application}

(a) Clinical material. The only criteria for the selection of patients for the clinical use of Toxiferine was the duration of the intended operative intervention, that is, whether an operation of more than one to two hours' duration was anticipated. Age, general condition, or concomitant diseases. (if these permitted curarization at all) were not taken into consideration. Our clinical material, therefore, consisted mainly of middle-aged to elderly adults. The drug was rarely administered to children, chiefly because such prolonged operations are less frequent in children. Toxiferine has not been given to infants or small children.

(b) Operations. The drug was used in long operations, mainly abdominal and thoracic surgery, such as partial gastrectomy (including bleeding añ̄ perforated ulcers), total gastrectomy, splenectomy, hemicolectomy, amputation of the rectum, cholecy'stectomy with choledochotomy for which a rather long operation was to be anticipated, resection of the pancreas, pneumonectomy, lobectomy, and resection of the esophagus and cardia. In addition, Toxiferine was used in the resection of advanced goitre and, less frequently, in protracted orthopaedic interventions, such as pseudoarthrosis, open reduction of old пractures, and so on, whenever strong curarization seemed appropriate; not every surgeon wishes it.

In urological operations we were more reserved: although we used Toxiferine without hesitation in operations for ureteral or renal calculi, or plastic surgery of the renal pelvis in patients in whom the appropriate investigations indicated intact renal function, we preferred not to use Toxiferine in patients in whom this could not be assumed. It is known from animal experiments that Toxiferine -as other synthetic non-depolarizing relaxants-is not reduced, but excreted quantitatively through the kidneys almost unchanged.

(a) Technique of Anaesthesia. Our anaesthetic procedure was as follows: after premedication with meperidine and atropine, anaesthesia was induced intravenously with thiopental. Intubation was then performed under succinylcholine apnoea. Anaesthesia was maintained with a $\mathrm{N}_{2} \mathrm{O}-\mathrm{O}_{2}$ mixture with or without the addition of small amounts of halothane. After the return of spontaneous respiration, Toxiferine was administered intravenously in a dose which produced complete paralysis of the spontaneous respiration of at least to such a degree that respiration could be controlled without resistance. In children, instead of intubation under succinylcholine apnoea, this was performed during spontaneous respiration under halothane drip anaesthesia. Intubation under Toxiferine relaxation would, of course, also be possible. We did not, however, see any 
reason to change the mede of intubation which is usual in our clinilic also for didactic reasons.

If there was sufficient spontaneous respiration at the end of the operation (measured with a flow-meter and compared with the values found before curarization), the patient was extubated. If there were no signs of residual curarization, that is, if the patient was able to open his eyes completely and, above all, to swallow, decurarization was not necessary and therefore omitted. If there was some residual curarization, we first administered atropine intravenously, then physostigmine* intravenously, and-according to the degree of the remaining curarization-perhaps pyridostigminet (generally $1 \mathrm{mg}$. intramuscularly and $1 \mathrm{mg}$. intravenously). If no signs of spontaneous respiration were detectable at all, at the end of the operation (this occasionally occurs in operations which, contrary to expectation, end as exploratory laparotomies) artificial respiration was continued at any rate until a measurable, though low, spontaneous respiration could be detected and then only decurarization was performed.

\section{EXPERIMENTAL RESULTS}

Histamine Effects

(a) On the skin. Intravenous injection did not cause cutaneous side-effects in any of the volunteers; no exanthematous reactions which could have been the result of a histamine release were observed.

In order to define possible histamine effects more exactly, we compared Toxiferine with other natural and synthetic non-depolarizing relaxants in the intracutaneous test. We injected dilutions of Toxiferine and of d-tubocurarine, methylcurarine, gallamine, physiological saline, and histamine. The individual relaxants were diluted according to their clinical effectiveness, on the assumption that Toxiferine is 10 times, methylcurarine 3 times, and gallamine 0.25 times as effective as d-tubocurarine. We investigated the substances in two different series of dilutions; one contained $30 \gamma$ Toxiferine per injection, the other $3 \gamma$ Toxiferine, and the corresponding amounts of the other relaxants. The reactions were fully developed after 10 to 15 minutes and wore off in the course of the next hour or two. The injection of physiological saline caused. only a slight unspecific reddening. All the relaxants caused more marked reddening and wheal, the intenşity being greatest with d-tubocurarine, medium with methylcurarine, and least with Toxiferine and gallamine. The two latter substances produced about equally strong reactions. The duration of the reactions corresponded to their intensity: the wheals and reddenings of the Toxiferine and gallamine injections wore off first, then those of methylcurarine, and lastly those of d-tubocurarine. Among the series of weaker dilutions, a slight reddening at the site of injection of d-tubocurarine could be observed after four hours. It, therefore, outlasted the effect of the injection of pure histamine.

(b) On salivary secretion. In our auto-investigations, at least those with small doses, intravenous injection of Toxiferine caused no increase in salivation, which

*Prostigmin.

†Mestinon. 
was marked only after d-tubocurarine. We cannot judge the effect on salivary secretion of higher doses ( $23 \mathrm{\gamma} / \mathrm{kg}$. body-weight) because atropine was given as premedication in order to eliminate secretion as far as possible. These doses caused complete deglutition paralysis of 15 to 20 minutes duration, so that even normal salivary secretion would have increased the danger of aspiration.

\section{Effect on Blood Coagulation}

Knowing that d-tubocurarine prolongs the prothrombin and coagulation timea property which is generally considered to be due to heparin release and because with clinical use of Toxiferine we had occasionally observed an unusual degree of parenchymatous haemorrhage during the operation, we also carried out prothrombin estimations (using the two-phase method) in some of our
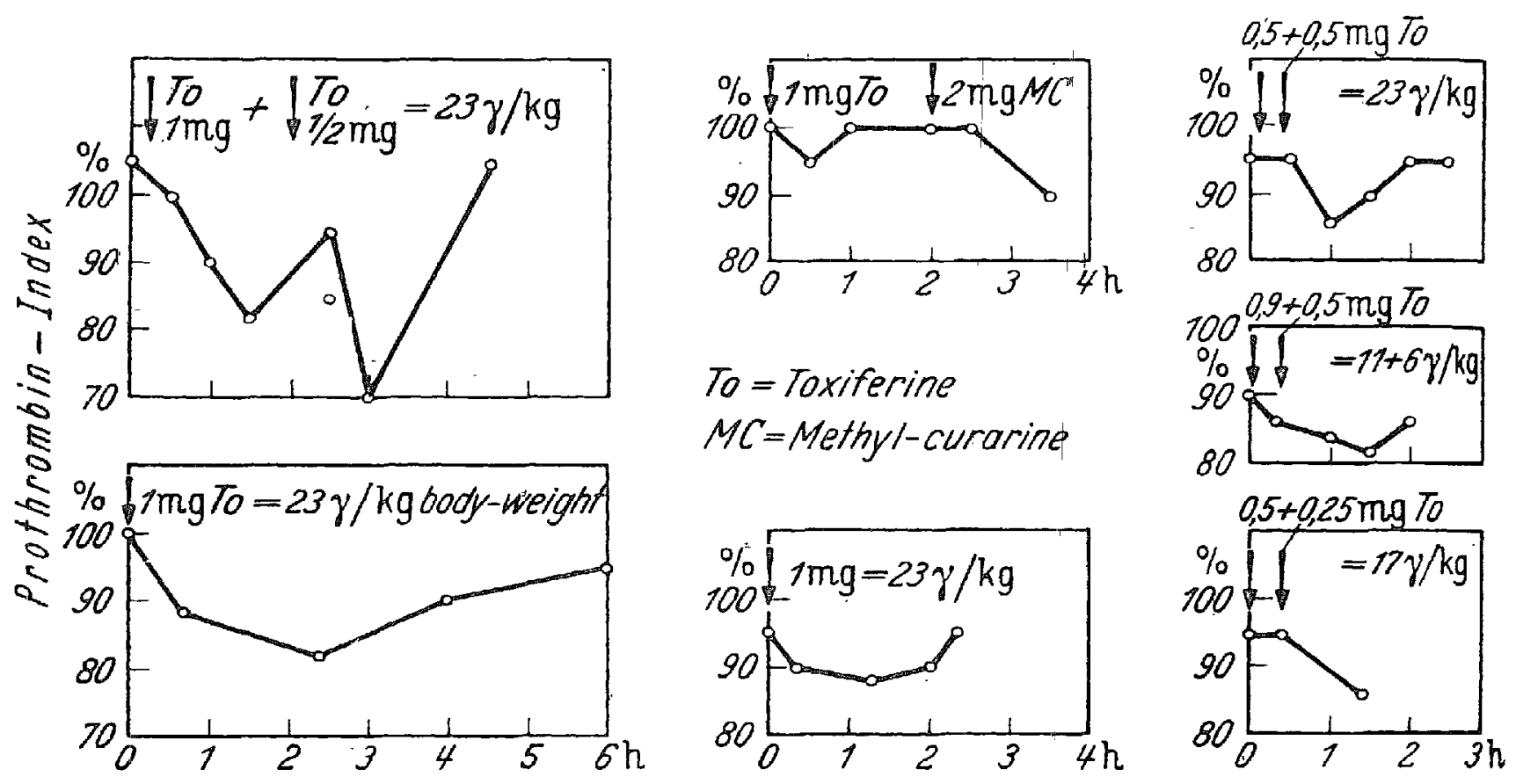

FIGURE 1. Changes in coagulation time in the hours following injection of Toxiferine: regular prolongation of coagulation time.

volunteers. The results varied considerably from test to test. Nevertheless, there was a regular fall in prothrombin which in some of the cases, however, especially at low doses, was only 5 to 10 per cent and, therefore, had no significance. At higher doses, the reductions were generally more marked (from 10 to 20 per cent). In subsequent tests at the same dose $(1 \mathrm{mg} .=23 \mathrm{\gamma} / \mathrm{kg}$. body-weight) however, the prothrombin reduction varied from 5 to 23 per cent in one individual subject and a definite relationship could not, therefore, be determined. At a further increased dose of $1.5 \mathrm{mg}$. (fractionate injection of 1 and $0.5 \mathrm{mg}$.), there was a reduction of 35 per cent. A corresponding slight prolongation of the coagulation time was occasionally observed. In contrast to d-tubocurarine with which the maximum effect on blood coagulation occurs a few minutes after the injection, we observed the maximum effect of Toxiferine only after one to two hours. 
Our clinical observations also agree with this: with laparotomy we hardly ever saw increased haemorrhage when severing the subcutaneous tissue and the muscular layers, unless an increase in blood pressure had occurred because the plane of anaesthesia was too light at the beginning of the operation; whereas/we repeatedly observed increased haemorrhage from the mucosa in suturing anastmoses, for example, with gastrectomies, although the circulation was constant and the blood pressure kept low.

We should like to emphasize that such an increased haemorrhagic tendehcy has been observed only in a small number of cases. One must take this difficulty into account, however, and, in cases in which increased haemorrhage hinders the preparation or evokes additional dangers (for example, brain tumors, liver injuries, and so on), be more reluctant to give large doses of relaxants.

In operations of long duration in which Toxiferine is indicated as relaxant, the maximum of the coagulation disturbance occurs during the course of the operation. In our opinion, there is no danger of increased secondary haemorrhage. None was observed in the cases we have treated to date.

Pulse Rate

Changes in the pulse rate immediately after the injection of Toxiferine, and attributable to the relaxant, have not been observed in our investigations. At the peak of curarization, with marked restriction of spontaneous respiration or during artificial respiration, there were, of course, especially in the first trials, occasional slight increases in the pulse rate (not exceeding $100 / \mathrm{min}$.) which were of a psychogenic origin and humanly understandable. In one volunteer who underwent a total of 15 such tests, the initial pulse rate remained unchanged for the whole duration of some of the later tests.

\section{Blood Pressure}

The same applies to the blood pressure values which were measured at intervals of one-half to two minutes. A significant fall in blood pressure following Toxiferine administration was never observed (in contrast, there was a fall in blood pressure of $20 \mathrm{~mm}$. systolic at times following evęn small doses of $\mathrm{d}$ Tubocurarine Chloride and dimethyl-d-tubocurarine). Occasionally, also at the peak of the curarization, there was a slight increase in blood pressure (again due to psychogenic reasons and sometimes perhaps to a rise in the $\mathrm{CO}_{2}$ tension) with subsequent decrease to the norm or somewhit below as the curare effect wore off.

\section{Dosse}

The mode of action of Toxiferine is the classical curarelike one, that is, nondepolarizing. The course of the paralysis, therefore proceeds in the same manner and order as that due to d-tubocurarine. Toxiferine, however, is about 15 times more effective in the human than d-Tubocurarine Chloride, as shown by comparative studies of the two substances.

(a) Effect on the ocular muscles. The influence on the ocular muscles is the first to be felt and also lasts the longest. The sensitivity of the individual ocular muscles also varies (one can observe this best as the curare effect wears off, since 
this takes place particularly slowly in the ocular muscles). From investigations with other non-depolarizing relaxants, it is known that the $\mathrm{Mm}$. recti interni are especially sensitive to curare. The same has been observed with regard to Toxiferine: as the last objective symptom before the effect wore off, there remained a divergent strabismus even when the patient was able to stand upright again. Only a very small amount of Toxiferine is apparently necessany to produce this paralysis: after intravenous injection of only $0.25 \mathrm{mg}$. Toxiferine (corresponding to $5.6 \mathrm{\gamma} / \mathrm{kg}$. body-weight) we were able to observe this effect, subjectively experienced as diplopia, without paralysis of the $M$. levator palpebrae. This was the smallest intravenous dose given in our tests and we are inclined to assume that even smaller doses would produce this paralysis. (This assumption is based on an observation made accidentally and involuntarily in one of our histamine tests. We intended to inject $30 \gamma$ Toxiferine intracutaneously and, due to incorrect technique, we apparently hit a small subçutaneous vessel. Within a few minutes the volunteer suffered from diplopia and strabismus. One has, however, to take into consideration that the same volunteer had received other relaxants in corresponding intracutaneous dosage, so that this incipient curarization might be attributed to a summation effect. Therefore, $30 \gamma$ cannot be considered as a dose causing initial paralysis of the ocular muscles.)

(b) "Head drop" dose. The "head drop" dose which is so important in the animal experiment is of no interest in the human. In our investigations, "head drop" occurred at the reduction of the grip strength to $15-30$ per cent of the norm. In other words, the "head drop" dose approximately corresponds to that which reduces the grip strength to 15-30 per cent of the norm.

(c) Influence on vital capacity and grip strength. With sufficiently high doses, the total skeletal musculature, including the peripheral musculature of the respiratory tract and the diaphragm, are paralysed during the further course of the curarization. In our tests, the effect on the respiration, measured by the vital capacity, and the reduction of the grip strength followed a parallel course, in that both decreased in a linear manner to the-minimum which was reached within five minutes, on the average. In figures, however, the reduction of the vital capacity was markedly less than that of the grip strength. A dose $(17 \gamma / \mathrm{kg}$. body-weight) which reduced the grip strength to about 40 per cent of the norm, reduced the vital capacity only to about 70 per cent of the initial value. An increased dose (23 $\gamma / \mathrm{kg}$. body-weight), which lowered the grip strength to 0 per cent, still left a vital capacity of 30 per cent. This difference must be attributed to a reduced sensitivity of the diaphragm because the remaining peripheral musculature of the respiratory tract as well as the skeletal muscles were paralysed. Where a sufficient spontaneous respiration and a relatively high vital capacity remained, there was pure diaphragmatic respiration.

Wh respect to the relationship between the reduction of the grip strength and the reduction of the vital capacity, Toxiferine corresponds to d-tubocurarine, whereas the effect of methylcurarine* on the vital capacity was even lower: the dose of $0.1 \mathrm{mg} . / \mathrm{kg}$. body-weight, for instance, reduced the grip strength to 0 per cent; the vital capacity, however, only to 60 per cent (in agreement with Sadove's results).

*Dimethyl-d-tubocurarine chloride. 
Whereas, at the onset of action, the vital capacity and the grip strength uniformly decrease, with the wearing off of the effect, the vital capacity is normalized more rapidly than the grip strength. After injection of $1 \mathrm{mg} .=23$ $\gamma / \mathrm{kg}$. Toxiferine, for instance, the grip strength was still less than 5 per cent at the time when the vital capacity had again reached 50 per cent. At the time when the vital capacity was at 80 per cent, the grip strength was only 20 per cent; in other words, 50 per cent of the vital capacity was reached after 17 minutes, 50 per cent of the grip strength only after 38 minutes. The effect of this substance on the grip strength therefore lasted twice as long as that on the vital capacity. The relatively prolonged influence on the grip strength is eyen more marked when Toxiferine is injected more slowly; especially in this respect there were marked differences in the effect in relationship to the speed of injection (see Figs. 2 and 3). With rapid injection, normalization of the grip strength and vital capacity is achieved more slowly than with slow injection. With rapid injection, however, the prolongation of the action on the grip strength was more marked than that on the vital capacity.

\section{Ruration of Action}

More than with other shorter-acting relaxants, the duration of action of Toxiferine depended on the dose administered. In addition, as mentioned before, it depends to some extent on the speed of the injection.

When increasing intravenous doses of Toxiferine $(0.25 \mathrm{mg} ., 0.5 \mathrm{mg} ., 0.75 \mathrm{mg}$., $1 \mathrm{mg}$.) were administered to a volunteer weighing $44 \mathrm{~kg}$, , restriction ${ }^{*}$ of the vital capacity below 70 per cent of the norm and of the grip strength below 40 per cent of the norm was found to be present for the following periods:

\begin{tabular}{lcc}
\hline \multicolumn{1}{c}{ Dose } & \multicolumn{2}{c}{ Duration of action } \\
\cline { 2 - 3 } & $\begin{array}{c}\text { Vital capacity below } \\
70 \text { per cent of the } \\
\text { norm }\end{array}$ & $\begin{array}{c}\text { Grip strength below } \\
40 \mathrm{per} \text { cent of the } \\
\text { norm }\end{array}$ \\
\hline $0.25 \mathrm{mg} .=5.6 \mathrm{\gamma} / \mathrm{kg}$. & $7 \mathrm{~min}$. & $8 \mathrm{~min}$. \\
$0.5 \mathrm{mg} .=11 \mathrm{\gamma} / \mathrm{kg}$. & $12 \mathrm{min.}$ & $18 \mathrm{~min}$. \\
$0.75 \mathrm{mg} .=17 \mathrm{rg}$. & $26 \mathrm{~min}$. & $37 \mathrm{~min}$. \\
\hline
\end{tabular}

Vital capacity and grip strength had returned to normal after the following lengths of time: $0.25 \mathrm{mg}$. $=5.6 \gamma / \mathrm{kg}$. in $9 \mathrm{~min}$. and $12 \mathrm{~min}$.; $0.5 \mathrm{mg}$. $=91 \mathrm{\gamma} / \mathrm{kg}$. in $15 \mathrm{~min}$. and about $20 \mathrm{~min}$.; $0.75 \mathrm{mg}$. $=17 \mathrm{\gamma} / \mathrm{kg}$. in $20 \mathrm{~min}$. and about $50 \mathrm{~min}$; $1.0 \mathrm{mg} .=23 \mathrm{\gamma} / \mathrm{kg}$. in $60 \mathrm{~min}$. and about $60 \mathrm{~min}$.

The duration of "head drop" after $23 \gamma / \mathrm{kg}$. was $16-17 \mathrm{~min}$. depending on the rapidity of injection; the duration of deglutition paralysis was $15-20 \mathrm{~min}$. after the same dose. A marked effect on the ocular muscles was observable for two hours. After this period, the volunteers were generally able to stand up and to walk-though somewhat unsteadily-on the level floor. Minor after-effects such as unsteadiness in "climbing stairs, incapacity to read for long because of slight 


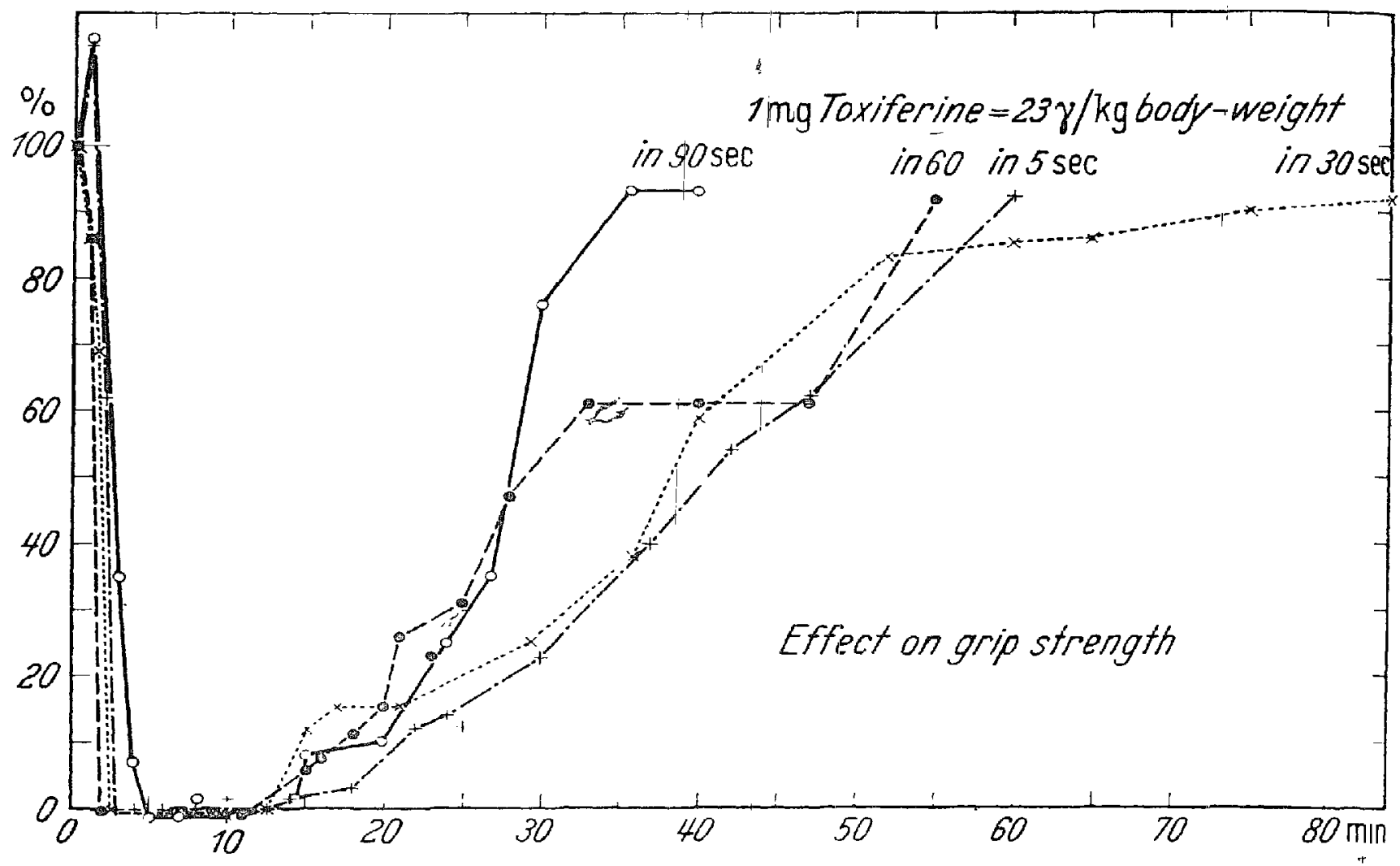

FigURE 2. Effect of $1 \mathrm{mg}$. Toxiferine on grip-strength (summary of the results of 4 trials).

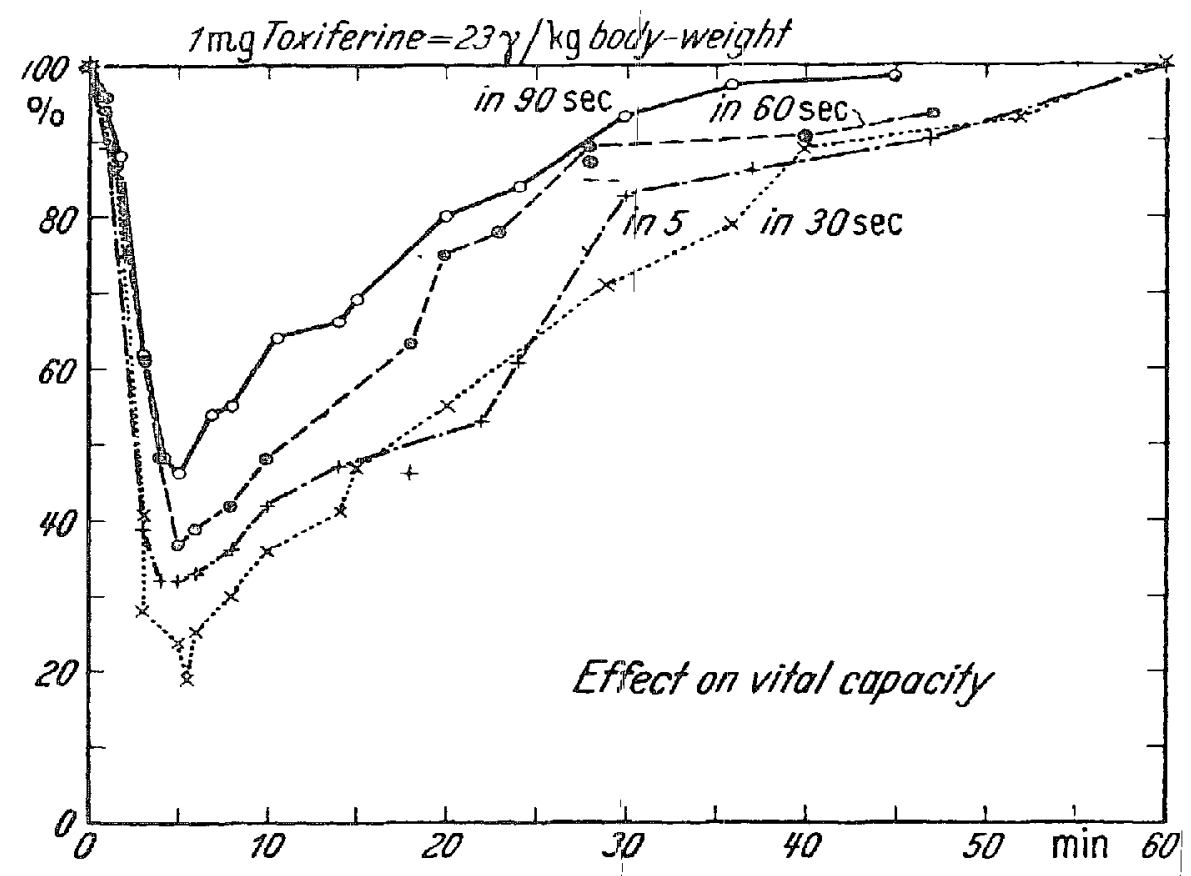

Figure 3. Effect of $1 \mathrm{mg}$. Toxiferine on the vital capacity (summary of the results of 4 trials). 
weakness in the ocular muscles, increased fatigability following repeated rapid movements could be observed even five hours after the injection.

In obese persons, the same dose per $\mathrm{kg}$. body-weight produced more marked effects of somewhat longer duration. This is in agreement with the fact known from experience with other curare preparations that the dose of a relaxant has to be reduced in the obese as well as for persons who are donsiderably underweight.

\section{Accumulation}

(a) With repeated Toxiferine administration. One of the most impressive properties of Toxiferine is its marked property of accumulation following repeated injections. Although this was to be expected because of the long duration of action of this substance and the slow excretion, known from animal experiments, we were repeatedly surprised at the extent of this accumulation.

In the first instance, we assessed these properties by subsequent injections of small doses of Toxiferine at short intervals of $15-20 \mathrm{~min}$. compared with equivalent doses of d-tubocurarine and methylcurarine (see Figs. 4 and 5). A very

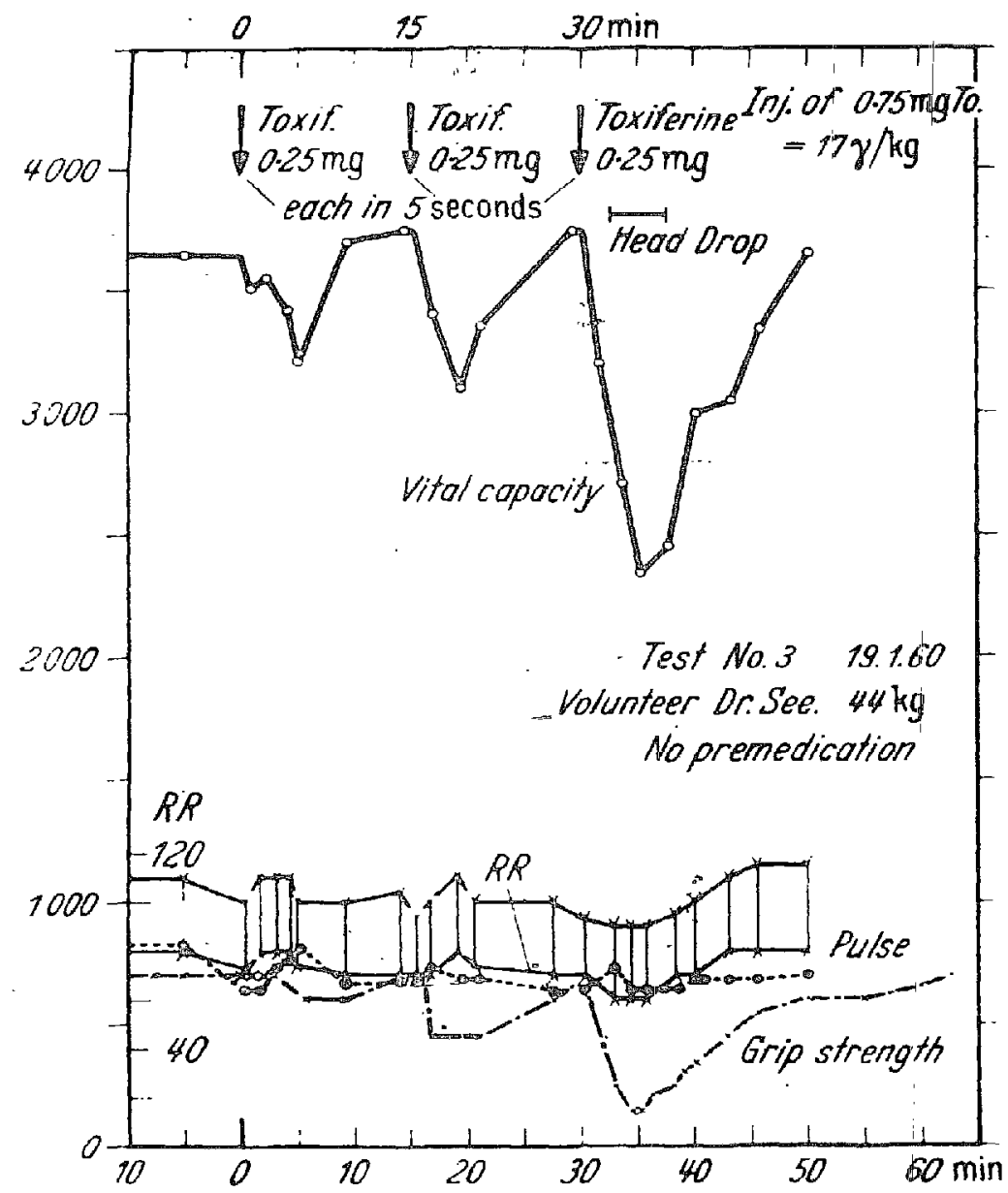

Figure 4. Cumulative effece of repeated intralvenous injections of $0.25 \mathrm{mg}$. Taxiferine; 


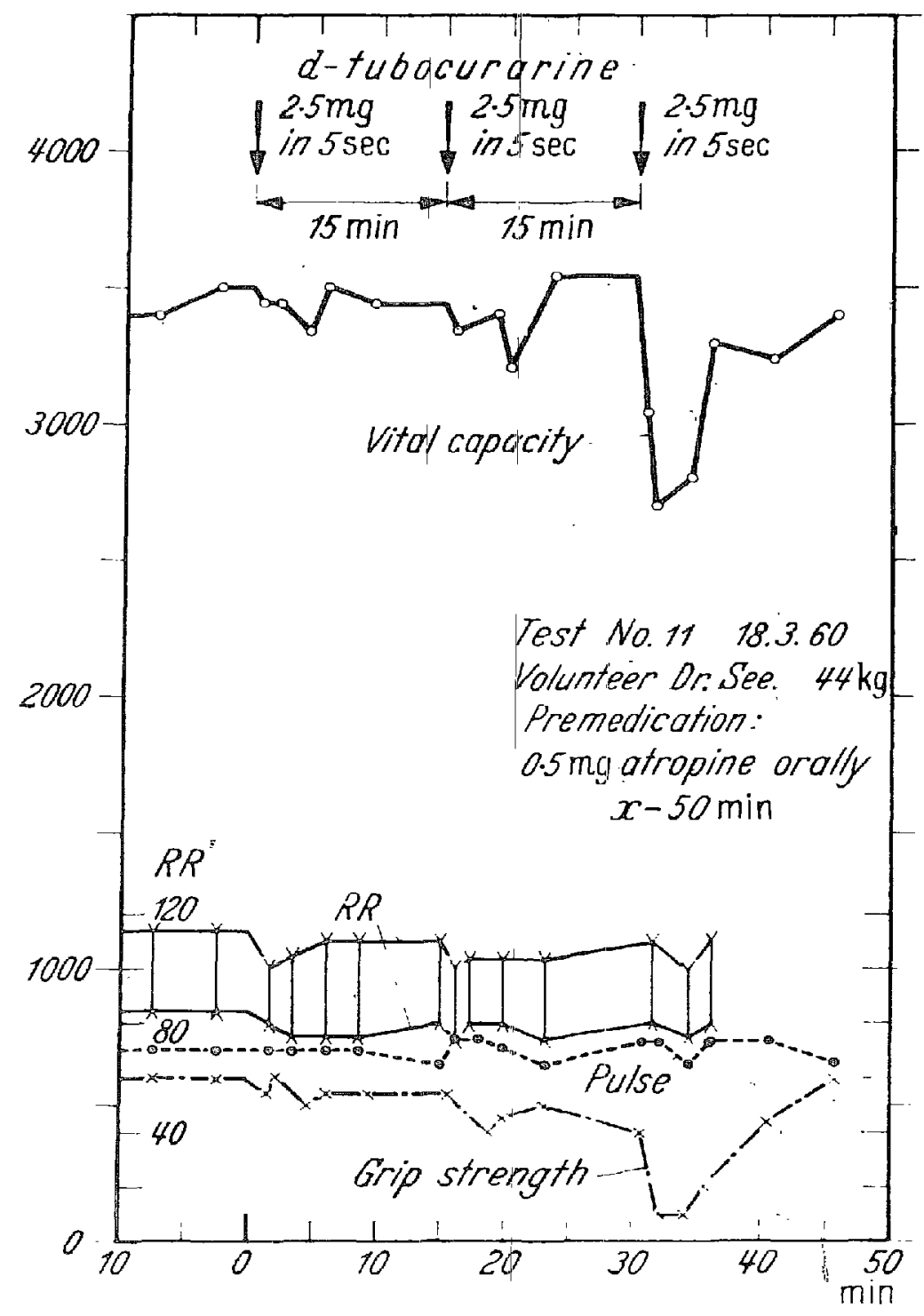

FIGURE 5. Cumulative effect of repeated injections of $2.5 \mathrm{mg}$. d-tubocurarine in the same volunteer $\backslash$ as in Figure 4 .

marked accumulation with regard to vital capacity and grip strength resulted from the administration of Toxiferine. Repeated doses of d-tubocurarine likewise produced these effects though they were less pronounced. Methylcurarine produced almost no accumulation with regard to vital capacity, which corresponds to its generally minor effect on the respiration, whereas a certain accumulation with regard to grip strength was observed. The differences between the individual relaxants were not as marked when the intervals between the individual injections were short.

(b) Combination with other relaxants. For this purpose, we changed the experimental conditions in such a manner that we allowed two hours to pass after the initial injection of $1 \mathrm{mg} .=23 \mathrm{\gamma} / \mathrm{kg}$. until, apart from the above mentioned slight after-effects such as easy fatigability of the musculature, no subjective 
curare effects were felt (objectively, these had worn off earlier). We subsequently injected $\frac{1}{2} \mathrm{mg}$. Toxiferine (that is, half the initial dose) in a first test, $2 \mathrm{mg}$. methylcurarine in a control test (that is, the dose which, as singlle dose in the same volunteer, had decreased the vital capacity to 90 per cent of the norm and the grip strength to 60 per cent), and $22 \mathrm{mg}$. suceinylcholine in a third test (the full relaxant dose calculated for this subject).

The results are shown in the Figures 6,7 , änd 8 . A second injection of $\frac{1}{2} \mathrm{mg}$. Toxiferine two hours after the injection of $1 \mathrm{mg}$. Toxiferine produced an equally strong and even longer lasting effect on the vital capacity and grip strength than the injection of $1 \mathrm{mg}$. Toxiferine given two hours earlier. Although the single dose of dimethyl-d-tubocurarine hardly made any impression on the volunteer, the effects of this second injection on the respiration were not the minor ones otherwise typical of methylcurarine: on the contrary, the respiratory impairment was in this case so strong that artificial respiration had to be performed for ten minutes. This had not been necessary with the injection of Toxiferine alone. The results prove that two hours after the injection of Toxiferine, a great part of this relaxant, at least half of the dose administered, must still be present and active. In contrast to this, the subsequent injection of succinylcholine two hours after Toxiferine administration had a ríormal effect: no cumulative effect was to be anticipated because this is a relaxant of the depolarizing type. However, there was no reduction of the effect. The muscle pains which appeared after the injection were also the same as those occurring after a single injection of succinylcholine.

(c) Combination with anaesthetics. The intensity and duration of the effect of the individual Toxiferine doses mentioned above apply to injections in conscious volunteers who- apart from small amounts of atropine administered with the highest doses of Toxiferine-had received no pretreatment. In any case, there is an additive effect on the muscle relaxation produced by Toxiferine during anaesthesia, and with some anaesthetics (for example, ether and halothane), a potentiating effect, with regard to both the intensity and above all the duration of the effect.

Side-Effects

No side-effects whatsoever have been observed in any of our tests with Toxiferine, neither irritation of the wall of the vein associated with pain at the site of injection nor any general complaints. A certain feeling of giddiness which occasionally appeared at the beginning of the paralysis also occurs with paralysis of the ocular muscle due to other causes, and disappeared when the volunteer closed his eyes. We have never observed exanthematous skin reactions, increased salivation, or changes in blood pressure or pulse rate.

\section{Possibility of Being Antagonized}

Toxiferine, as other non-depolarizing relaxants, can be antagonized by cholinesterase inhibitors. In our tests, we did not make use of this possibility as we were anxious to observe the wearing off of the effect. We shall revert to this problem when discussing the clinical use of Toxiferine. 


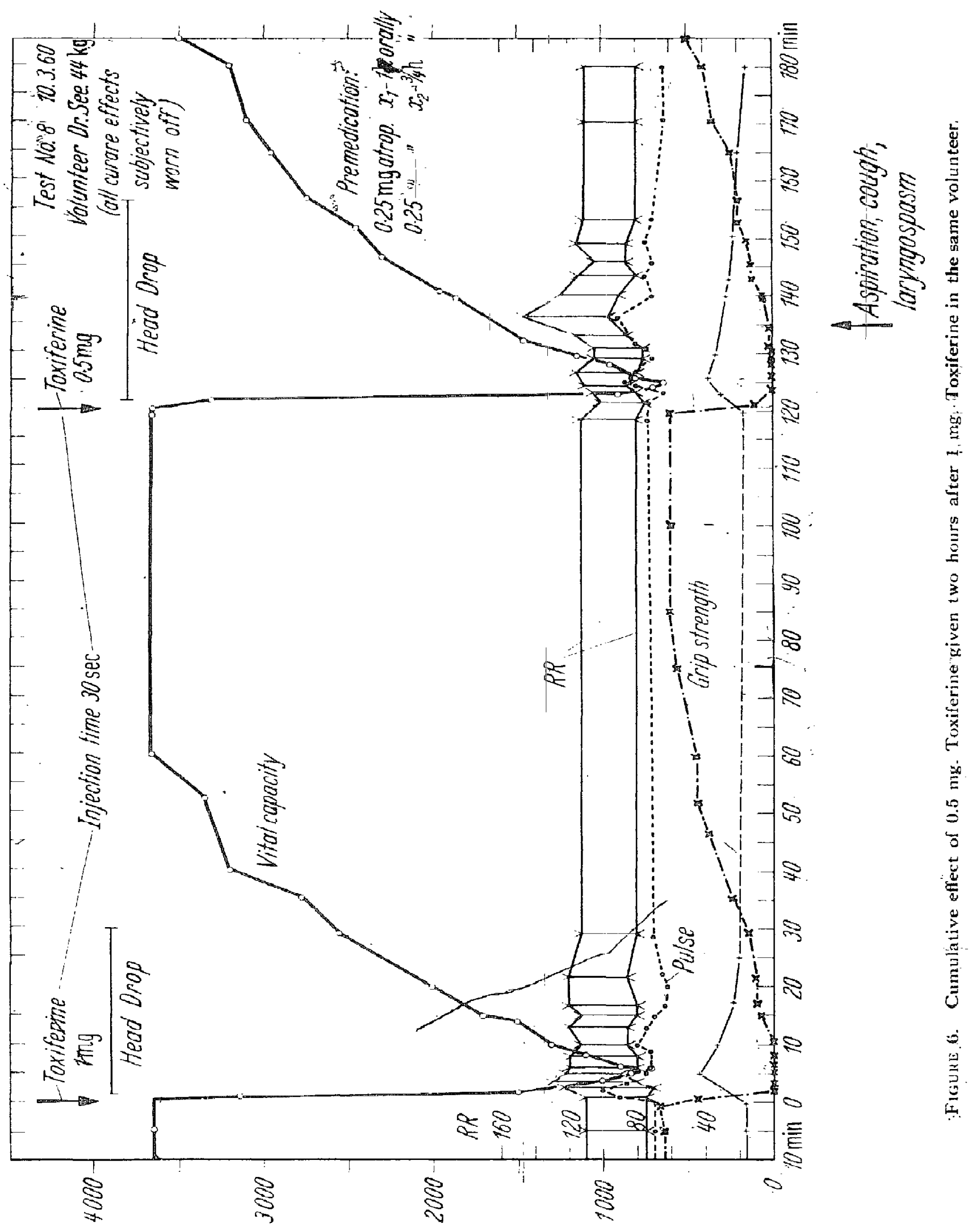




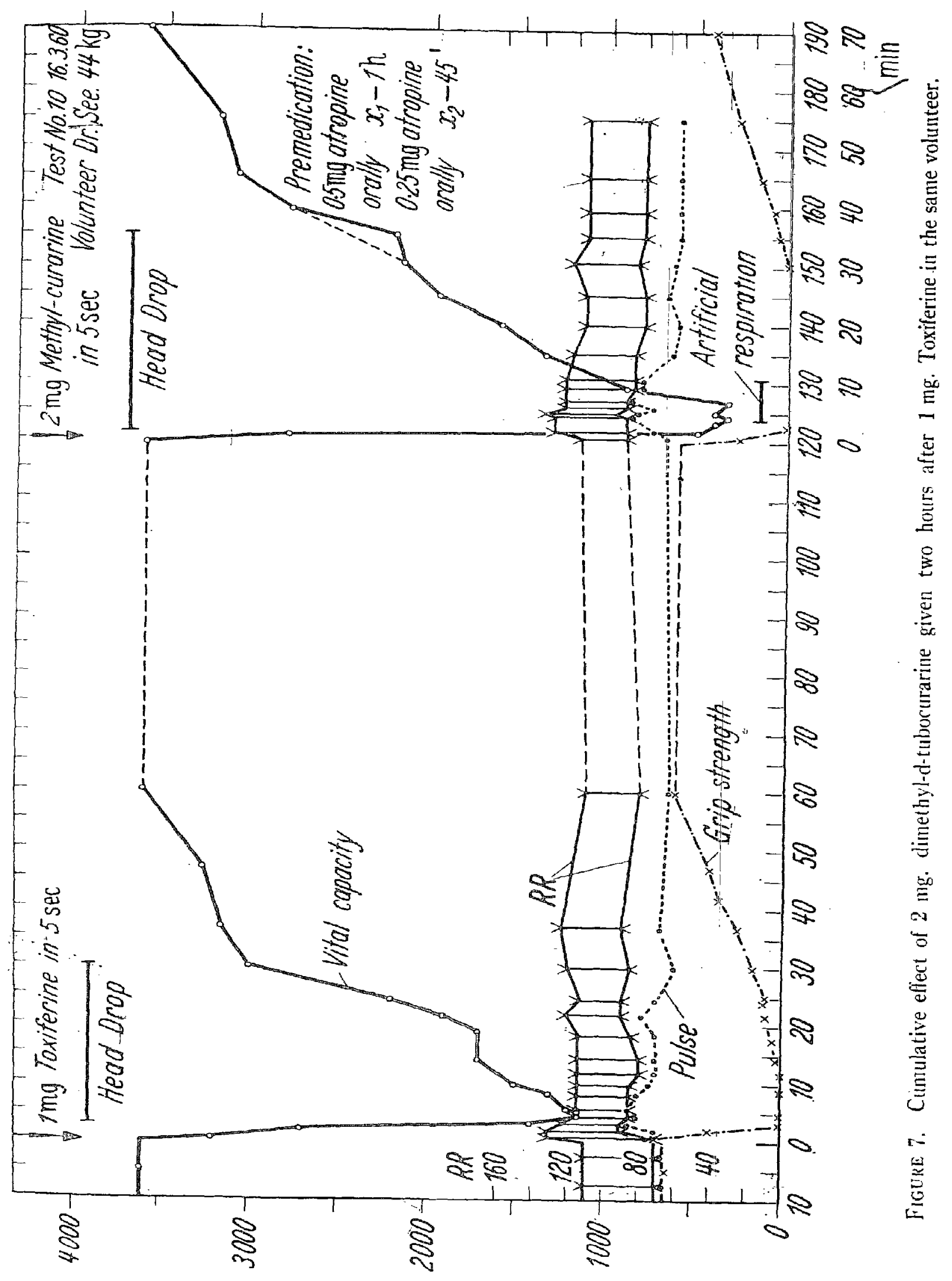




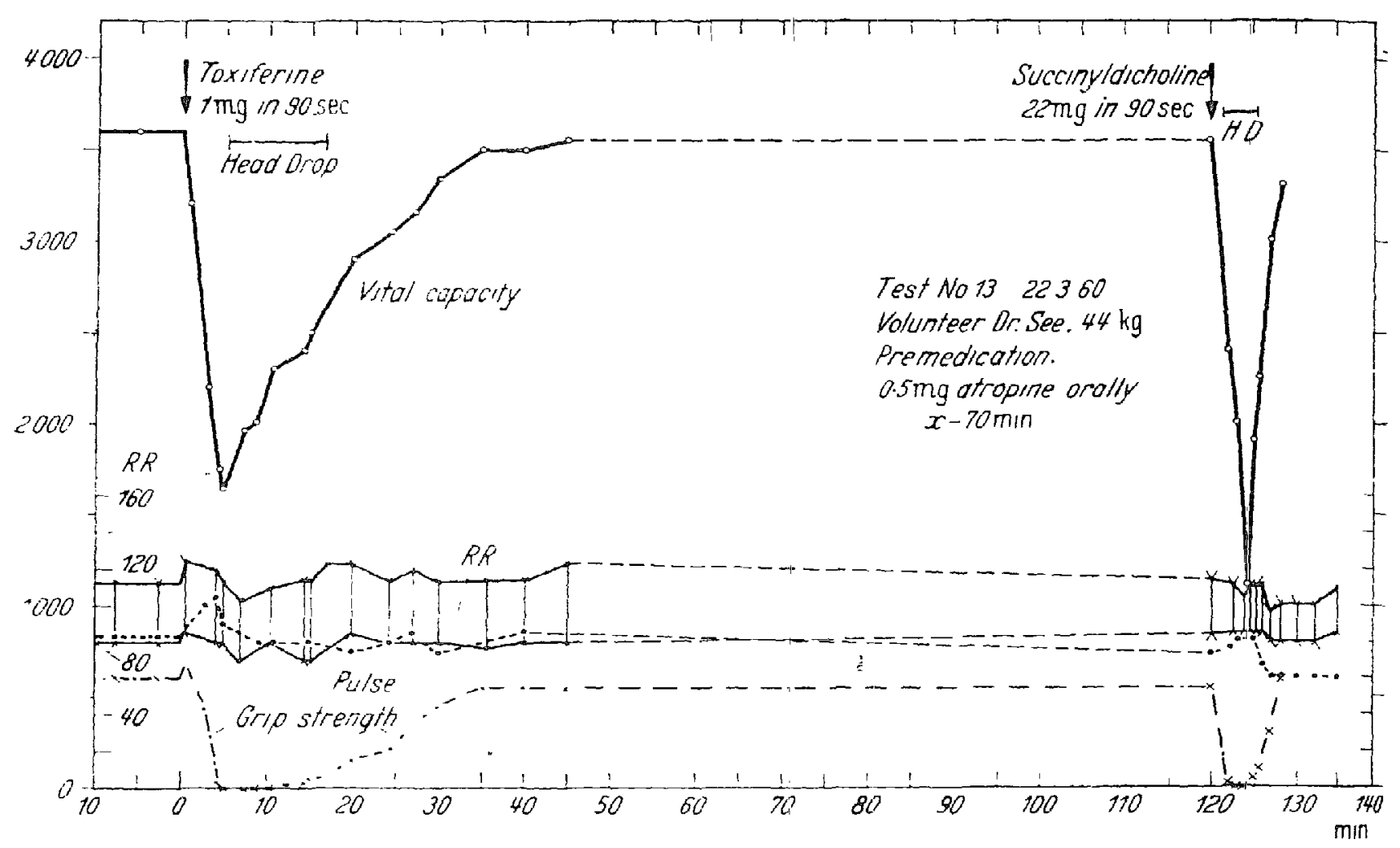

FIGURE 8 . Absence of cumulative effect of $22 \mathrm{mg}$. succinylcholine giventwo hours after $1 \mathrm{mg}$. Toxiferine in the same volunteer.

\section{CIINICAL Results}

\section{Histamine Effects}

As in the tests, we did not observe histamine effects with the clinical use of Toxiferine. Laryngospasm, bronchospasm, or other manifestations which might be attributed to histamine release never occurred, although we intentionally excluded antihistaminics from the pretreatment of cases chosen for Toxiferine administration.

\section{Pulse Raté and Blood Pressure}

With regard to the effects on circulatio

erine administration under andesthesia also confirms the results obtanied in volunteers. There were no effects on circulation which could have been attributed to Toxiferine. In the majority of cases, anaesthesia was maintained with halothane. In these, there was occasionally a fall in blood pressure and pulse rate following complete relaxation and some minutes after respiration was controlled, especially if this was performed as a single phase direct pressure respiration. This effect is the result of the rapid flow of halothane and not of the muscle relaxant. Such an effect was never observed when subsequent doses of Toxiferine were injected during the course of the operation. Even more clearly than these observations, the results of our auto-investigations confirm that Toxiferine has no such effect on the circulation. 


\section{Clinical Dosage}

In order to achieve strong relaxation for protracted operation;, we generally injected $2 \mathrm{mg}$. Toxiferine at the beginning of the operation. In cachectic or considerably underweight patients, we reduced the dose to $1-1.5 \mathrm{mg}$. In almost all the cases, complete paralysis of spontaneous respiration was achieved within one and a half to two minutes with these doses, or at least such a restriction of the respiration that it could easily be controlled. If, in very muscular men, respitatory paralysis was not achieved with $2 \mathrm{mg}$, a maximum of a further $\frac{1}{2}$ to $1 \mathrm{mg}$. was immediately injected. Only in occasional cases were $3 \mathrm{mg}$. required,

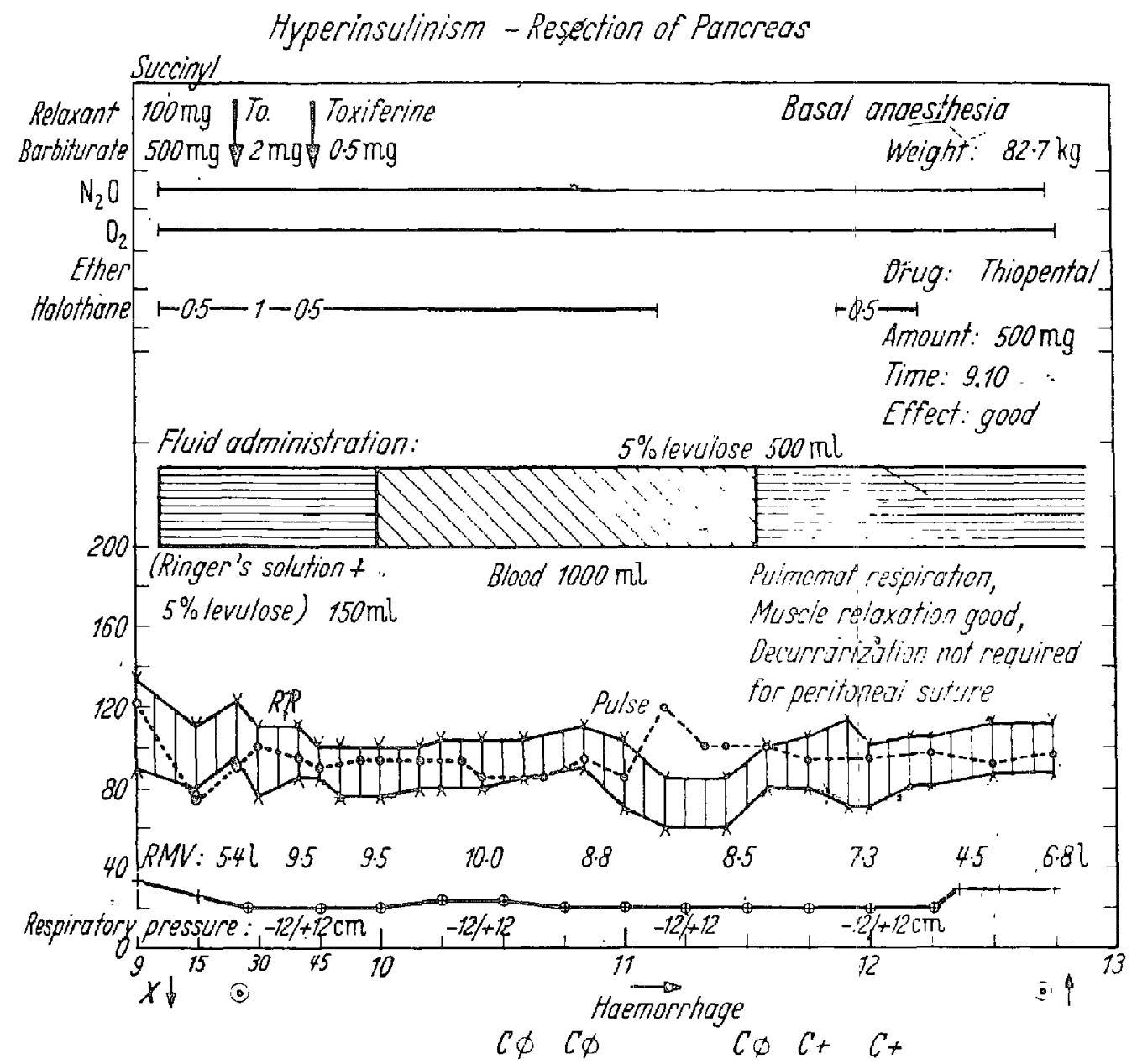

FIGURE 9. Anaesthetic data sheet showing long-lasting relaxation with Toxiferine in an operation for pancreatic tumor.

and never more. The duration of adequate muscle relaxation (to fulfill even the highest demands) after single injection of the aforementioned dose was 45 to 130 min. When increase of muscle tension or reappearance of spontaneous respiration began to interfere with the operation, we administered either $\frac{1}{2} \mathrm{mg}$. Toxiferine or 1 to $2 \mathrm{mg}$. methylcurarine if the operation was still expected to continue for some time, and this provided further relaxation for a good hour, or in some cases even longer. There is no contraindication to the additional administration 


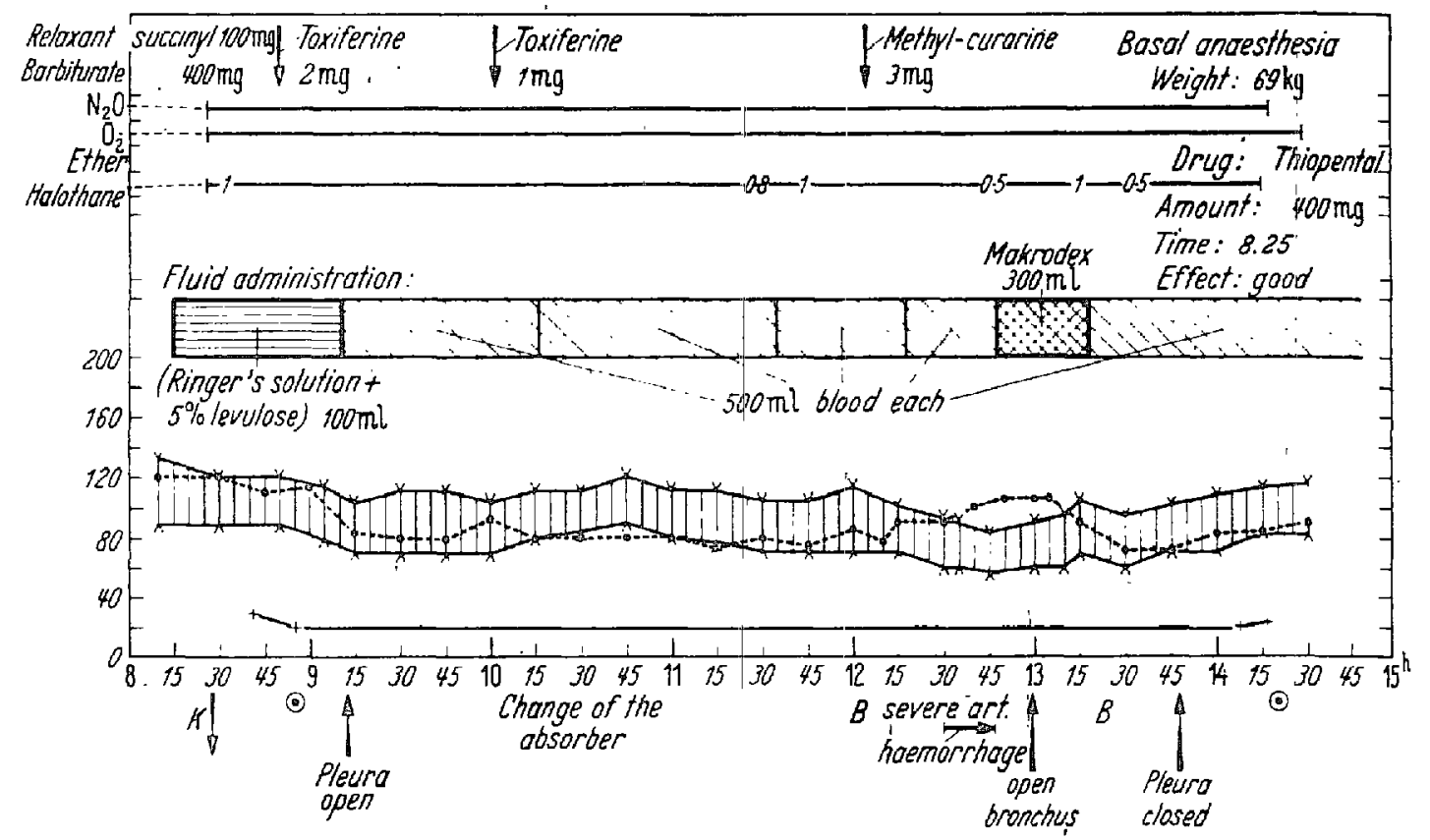

FIGURE 10. The anaesthetic data sheet showing combined use of Toxiferine and other relaxants for difficult lobectomy.

of succinylcholine for a short-lasting relaxation which may be necessary after the Toxiferine effect has completely disappeared. In our auto-investigations it has been proved that this is possible without danger. We wish, however, to point out that it is generally impossible to await the complete fading of the Toxiferine effect during the operation. In such cases, we occasionally observed that succinylcholine had an insufficient effect, or that relatively high doses were required in order to achieve the necessary relaxation. This might result in difficulties at the end of the operation, if the spontaneous respiration does not recur immediately and it cannot easily be/determined to what extent the paralysis is due to Toxiferine and to $v$ at extent to succinylcholine. Although no serious consequences result from this-at most, the patient must receive artificial respiration after the end of the operation-we tend to follow the repolarizing relaxant Toxiferine by a small dose of the likewise repolarizing relaxant methylcurarine if a second injection is necessary. In this case, we are certain of being able to reverse the effect. Or, if only a short-lasting relaxation is required, we prefer to inject only the amount of succinylcholine generally required for a sufficient relaxation. If this dose is ineffective, relaxation should not be forced by higher doses of succinylcholine. If worse comes to worse, one can try increasing the depth of anaesthesia.

For the maintenance of the anaesthesia, the aforementioned doses with theaddition of a small amount of halothane (we generally administered only 0.5 per cent and never exceeded $i$ per cent) had: a longer and more even effect than nitrous oxide-oxygen alone. There seems to be a true potentiation. The possibility of easy hyperventilation typical of halothane anaesthesia is a particularly favourable feature as the effect of Toxiferine wears off and often avoids the necessity of a second injection. 


\section{Possibiluty of Being Antagonized}

If decurarization is required, the following technique has proved to be appropriate: if only a slight residual curarization remains on the return of sufficient spontaneous respiration, the patient not yet being able to open his eyes completely and having difficulty ${ }^{t} \mathrm{in}$ swallowing, intravenous injection of $\frac{\mathrm{r}}{2} \mathrm{mg}$. physostigmine following the administration of $\frac{1}{4}$ to $\frac{1}{2} \mathrm{mg}$. atropine will rapidly abolish these slight residual effects. In case of more pronounced residual curarization, we gave an additional $\frac{1}{2} \mathrm{mg}$. physostigmin or $5 \mathrm{mg}$. pyridostigmin intramuscularly. If sufficient spontaneous respiration had not been re-established at the end of the operation, we administered $1 \mathrm{mg}$. physostigmin intravenously following the intravenous injection of $\frac{1}{2} \mathrm{mg}$. atropine. At our Toxiferine dosage, higher doses were never required to re-establish normal spontaneous respiration. In order to avoid recurarization which might be expected because of the relatively short-lasting effect of physostigmin, when compared with the duration of the effect of Toxiferine, we additionally administered $2.5 \mathrm{mg}$. pyridostigmin intravenously and $2.5 \mathrm{mg}$. intramuscularly. With this procedure we never observed recurarization. However, we always awaited the return of spontaneous respiration, even if only to a slight extent, before decurarization was performed.

\section{Accidents or Deaths}

To date, we have not observed any accidents or deaths which could have been attributed to the use of Toxiferine.

\section{Discrission AND CONClusions}

\section{Indications}

(a) Operations of long duratıon. Because of its intensive and prolonged effectiveness, Toxiferine has proved to be excellent for protracted operations requiring strong, long-lasting, even muscle relaxation. In these cases Toxiferine can be used as the sole relaxant. Because it has no histaminic effects, there are no contra-indications to its use in allergic or asthmatic patients. For operations of unpredictable duration, Toxiferine can be used in low dosage as the basic relaxant and, if necessary, its effect increased by methylcurarine or another repolarizing rekaxant.

(b) Tetanus. It so happened (it was, in fact, a happy coincidence) that at the time when Toxiferine was at our disposal we had only such mild cases of tetanus that no curarization was necessary at all. Thus, to date, we have had no opportunity to use Toxiferine in cases of tetanus, but we are convinced that it would be especially appropriate for such cases.

(c) Neurological and rheumatic diseases. Its even and long-lasting effect also justifies the attempt to use Toxiferine (subcutaneously in doses of $0.5 \mathrm{mg}$. to $1 \mathrm{mg}$.$) in spastic diseases and contractures in the neurological field, as well as in$ rheumatic diseases, although, of course, in correspondingly lower dosage and under the supervision of an anaesthetist or physician who is experienced in the technique of intubation and artificial respiration. 


\section{Contraindications}

(a) Short operations. As shown by our tests, the duration of the effect of Toxi. ferine depends to a considerable extent on the dose. Toxiferine in lower dosage could, therefore, also be used for shorter operations. There is, however, on point in this. For short interventions there are quite a number of very good short-acting relaxants which are easier to handle.

(b) Myasthenia gravis. Myasthenia gravis pseudoparalytica represents a true contraindication for any use of curare and therefore all the more for Toxiferine.

(c) Disturbances of electrolyte and acetylcholinesterase metabolism. As mentioned before, we are somewhat more reluctant to administer Toxiferine in cases with impaired liver function or in cases in which there is a tendency to haemorrhage from the very beginning or in which an increased parenchymatous haemorrhage might considerably disturb the operation. In severe disturbances of electrolyte and acetylcholinesterase metabolism, it is preferable to avoid the use of powerful and long-lasting relaxants.

\section{SUMMARY}

The Calabash alkaloid Toxiferine is the most potent and long-acting relaxant of the curare group available to the clinic. As little as $2 \mathrm{mg}$. produces sufficient relaxation for all operative interventions in adults, of a marked degree for 30 minutes and slowly wearing off during the next 30 minutes.

As shown in 30 auto-investigations and 100 clinical cases, the drug is approt priate for muscle relaxation during operations of more than one hour duration. In addition, it is of value as a "basic relaxant": hecause it can be antagonized by Prostigmin and can be combined with other relaxants.

Only minor side-effects were observed: there was no marked histamine release or pronounced effect on blood pressure and pulse rate. There were no accidents or deaths among our cases.

Further clinical investigations of Toxiferine are justified, especially for long. lasting relaxation in cases of tetanus and neurological disease. Contraindications are: short-lasting operations; myasthenia gravis pseudoparalytica;-disturbances of electrolyte and acetylcholinesterase metabolism.

\section{RÉSUMÉ}

Les relaxants musculaires qui existent actuellement n'apportent pas encore toute satisfaction à l'anesthésiologiste en ce qui concerne la durée de leur action, la possibilité d'être inhibé par un antagoniste, et l'absence d'efffets secondaires. C'est pourquoi il est justifié de poursuivre les recherches en vue de mettre au point de nouveaux relaxants.

L'isolement de la substance pure et la détermination de la structure chimique des alcaloîdes les plus importants extraits du Calabash-curare, par P. Karrer et II. Schmid, en 1958, ont éveillé le désìr d'expérimenter la Toxiférine au point de vue clinique. Les premiers esșais pharmacologiques et cliniques ont été réalisés par Waser et Harby. Au cours de nos recherches, la Toxiférine s'est avérée, par rapport à d'autres relax̧ants non-dépolarisants, ne provoquer que de 
minimes effets secondaires de type histaminique. Le pouls et la T.A. ne sont pas notablement modifiés par des doses cliniques. L'action est plus marquée et plus prolongée que celle des alcaloïdes naturels du curare connus jusqu'à présent. Chez l'adulte, il suffit d'une dose de $2 \mathrm{mg}$ pour produire une relaxation durant de 40 à 120 minutes, qui "permet toutes les interventions. Chez le sujet conscient et bien portant, une dose de $1 \mathrm{mg}$ entraîne une diminution moyenne de $50 \%$ de la capacité vitale et jusqu'à $10 \%$ de la force musculaire. La dépression de la capacité vitale est d'une durée très nettement plus brève (environ $20^{\circ}$ minutes) que la diminution de la force de préhension (environ 40 minutes). Les sujets du sexe féminin et les débilités répondent à des doses ne dépassant pas $0,7 \mathrm{mg}$, de la manière précédemment décrite.

Cliniquement, ce médicament s'est avéré efficace dans plus de 100 anesthésies pratiquées par les auteurs. Il est indiqué comme relaxant (éventuellement comme relaxant de base) dans les interventions chirurgicales devant durer plusieurs heures. Il n'a pas été nécessaire de dépasser la dose de $3 \mathrm{mg}$, la plus élevée qui ait été utilisée jusqu'à présent, car la répétition des injections produit une véritable accumulation. On a également constaté que la Toxiférine pouvait être associée à la tubocurarine, à la diméthyl-d-tubocurarine, à la gallamine, etc., de même qu'à l'Halothane, si la concentration de ce dernier ne dépassait pas $0,5 \%$ de l'air destiné à être inspiré. Tóutefois des étudè̀s plus approfondies paraissent nécessaires dans les cas d'interventions chirurgicales majeures de longue durée requérant une relaxation prolongée (dans les cas de tétanus gravissime par exemple).

\section{REFERENCES}

1. Berlag, F.; Bernauer, K.; von Philipsborn, W.; Waser, P.; Schmid, H.; \& Karrer, P. Helvet. chim. Acta 42: 394 (1959).

2. Bernauer, K.; Berlage, F.; von Philipsborn, W.; Schmid, H. \& Karrer,'P. Über die Konstitution der Calebassen-Alkaloide aus Strychnos toxifera. Helvet. chim. Acta 41: 2293 (1958).

3. FrEY, R. Vergleichende Untersuchungen der muskelerschlaffenden Mittel. Der Anaesthesist 1: 11 (1952).

4. FREY, R. Ergebnisse der Chirurgie und Orthopädie 38: 286 (1953).

5. FREY, R. Vergleichende Untersuchungen der Wirkungen muskelerschlaffender Mittel auf das Atemzentrum. Der Anaesthesist 1:33 (1952).

6. FrEy, R. Die Muskelrelaxantien. In Frey, Hügin, \& Mayrhofer, Lehrbuch der Anaesthesiologie. Heidelberg: Springer (1955).

i. SiEBECK, R., \& FREY, R. Die Wirkung muskelerschlaffender Mittel auf die Augenmuskeln. Der Anaesthesist 2: 138 (1953).

8. Waser, P., \& HARBEck, P. Erste klinische Anwendung der Calebassenalkaloide. Der Anaesthesist 8: $193(1959)$. 